\title{
Prognostic Factors of Early Neonatal Sepsis in the City of Cartagena Colombia
}

\author{
Jaime Lorduy Gómez ${ }^{1}$, Stephanye Carrillo González ${ }^{1}$, Ruby Elena Muñoz Baldiris ${ }^{1}$, \\ Anderson Díaz-Pérez ${ }^{1,2} \&$ Iris Perez ${ }^{3}$ \\ ${ }^{1}$ Corporación Universitaria Rafael Núñez, Facultad de Ciencias de la Salud, Cartagena de índias, Colombia \\ ${ }^{2}$ Universidad Simón Bolívar, Facultad de Ciencias de la Salud, Barranquilla, Colombia \\ ${ }^{3}$ Universidad Autonoma de Ciudad Juarez, México \\ Correspondence: Jaime Lorduy Gómez, Bacteriólogo, Especialista en Microbiología Clínica, Msc Epidemiología. \\ Corporación Universitaria Rafael Núñez, Programa Instrumentación Quirúrgica, Cartagena de índias, Colombia. \\ Orcid: https://orcid.org/0000-0001-8941-5592. Tel: 57-317-267-2845. E-mail: jaime.lorduy@curnvirtual.edu.co
}

\author{
Received: August 1, 2018 Accepted: August 23, 2018 Online Published: November 5, 2018 \\ doi:10.5539/gjhs.v10n12p30 URL: https://doi.org/10.5539/gjhs.v10n12p30
}

\begin{abstract}
Introduction: The obstetirc or noenatal risk factors, are in many cases the major evidence to define and forecast of an early neonatal sepsis, considering that a newborn that has lived less tan 72 hours presents unspecified clinical manifestations and the diagnostic exams utilize infectious and inflammatory markers, with there being very litttle scientific evidence to support and establish an early diagnosis. Objective: Associate the obstetric and neonatal risk factors with the presence of early sepsis in Cartagena.
\end{abstract}

Materials And Methods: A retrospective study of cases and controls was conducted. The sample consisted of 183 cases and 366 controls, including pacients who met simultaneously inclusion and exclusion criteria. A bivariated analysis and a multivariated model of regression logistics were used.

Results: Among the associtated variables and early sepsis in which it was able to define the risk that is found when there is a premature membrane rupture $>18$ hours (OR 9,57 IC 95\% 4,12-22,26), premature newborn (OR 8,19 IC 95\% 3,66-18,3), the presence of maternal fever (OR 6,49 IC 95\% 3,43-12,3), marital status (OR 5,89 IC 95\% $3,42-10,15)$ and level of education (OR 4,80 IC $95 \%$ 2,63-8,77).

Conclusions: The mechanisms of fetal evaluation and maternal prophylaxis should be prioritized in the cases of pregnant women that present a premature membrane rupture $>18$ hours, and have kids who were born premature and living in couple with a low level of education.

Keywords: newborn, risk factors, sepsis, infectious disease vertical transmission (MeSH)

\section{Introduction}

It is estimated that in the world for every 1000 live births, 21 die before completing the neonatal period, in Colombia the noenatal mortality apports $62 \%$ of the infant mortality (Peña, y otros, 2016) and at least $41 \%$ of those deaths present themselves before the 5 years which happens in the noenatal period (Ministerio de salud y protección social, 2016).

The early neonatal sepsis (ENS), is defined as a clinical syndrome characterized by the presence of a systematic infection which is proven by a blood test of the cerebrospinal liquid (CSL) positive to bacterias, fungis or virus; that is manifested in the first 72 hours and reflects a vertical transmission (Anaya-Prado, Valero-Padilla, Sarralde-Delgado, Sánchez-González, Montes-Velázquez, \& Gil-Villarreal, 2017; Coronel, 2009).

One of the characteristics of this disease is that it occurs more frequently in preterm infants, those of whom show a main characteristic of being under weight at birth and a immunological immaturity (Pérez, Lona, \& Quile, 2015). Prematurity is attributed as a risk factor in $28 \%$ of cases of neonatal mortality (Cabanillas Castillo, 2014).

Another important factor associated to early neonatal sepsis, is the premature rupture of the membrane (PRM) that happens one out of every three premature births; the principal cause is associated to intra amniotic infection (Ortiz Maldonado, 2014) evidencing a major susceptability in those newborns (NB) pre terms who are exposed to maternal infections, like is a yeast infection at the end of the pregnancy, with amniotic disruption of the membrane 
(Pérez, Lona, \& Quile, 2015).

Other less studied factors include, the appearance of early neonatal sepsis, related to sociodemografic aspects like the rural origin, level of education, marital status; which are not considered in the majority of the studies, but apport significance in the explanation of the pathology.

Due to the nonspecific clinical manifestations during the neonatal period and the difficulties in obtaining the oportune results from the microbiologicall exams, the epidemiological information allows to identify the pacients with a major risk of a sepsis appearance and help to value the utility of the application of the universal preventative measures (Pérez, Lona, \& Quile, 2015). It is estimated that more than $95 \%$ of the epidemiological information is originated from developed countries, where the indicators differ from the normally observed, in growing countries.

Because of all the above the objective to the present study consists in establishing the principal factors of diagnosis in the mothers of newborns that are associated with the presence of early neonatal sepsis.

\section{Methods and Materials}

A retrospective study of cases and controls was done, in newborns from a private institution in the city of Cartagena, between the years 2016-2017. The criterias were defined from eligability for the groups of study; considering the criteria of inclusion of the involved cases to every live newborn, of ages inferior to 72 hours, with the diagnosis of early neonatal sepsis by clinical criteria and laboratory blood cultures taken in the intensive neonatal care unit of the institution. Consequently the criteria of exclusion in the cases that include the kids with mothers that have some type of immunological deficiency, kids with mothers that have TORCHS syndrome or those newborns with major congenital malformations. Likewise, it was defined that the inclusion criteria of the controls would consider all newborns who were healthy, by clinical diagnosis or laboratory evidence upon leaving the institution and who have returned healthy for a control appointment at 72 hours. . Likewise, mothers who had some type of immunodeficiency were excluded from all controls.

It was defined for the sample calculation a case control relationship of 1:2. And the risk factors that apport in minor proportion to the generation of cases of early neonatal sepsis and the respective reason of disparity was equally considered. The calculation of the sample for the cases and controls took place in the Epidat 4.2 program and of which where taken 183 cases and 366 controls with a $95 \%$ of trust factor, a power of $80 \%$ and the correct application of continual from Yates.

Contingency graphs where created that allowed evidence the statistics in association between independent variables and the possibility to develope early neonatal sepsis. For the bivariated analysis a statistic association chi-square with correction from Pearson was used; for the intercrossing of polyatomic qualitative variables or of the dichotomous with expected major values over five in each cell. The same correction study of Fisher was utilized, for the dichotomous variables, with at least one value less than the expected five. The independence of the quantitative variables was observed by the $U$ of Mann Whitney study considering that the data did not comply with the expected. Putting in consideration the significant statistics associated with the value of $p \leq 0.05$.

The force of association was determined by calculating the values of reason for disparity and its respective intervals of confidence, using methods of binary logistic regression that helps identify the OR (ajustments) for the variables that the bivariated analysis are associated with, a p- value $<0,20$ or have a plausible relation with the cases of early neonatal sepsis. Similarly and with the objective to ajust the OR there was a construction of a model included, the posible confusers that were theoretically defined by the study of Mantel and Haenszel.

The data was taken from secondary sources, which were provided by an anonymous database, all this with the authorization of the ethics committee of the institution, which supported the use of the information only for research purposes. The present study, in association with the Resolution 008430 of the ministery of health in Colombia title II. Of the investigation of humen beings. Chapter 1. Of the ethic aspects of investigation in human beings. Articul 11, catalogued as "no risk" due to the secondary information, and not establishing direct contact with the people, and guaranteeing the confidenciality for the registered information in the data base, due to non existing identification codes, or names of the people in the study for completion of the objectives.

\section{Results}

The collection of information, the established limit was exceeded and a total of 186 cases and 368 controls were obtained.

The bivariated analysis of the association between variables with them being obstetric, neonatal and that were in relation to the maternal infectious pathology, and the presence of early neonatal sepsis.

The variable analysis of sociodemographic evidence has important relations to the cases of early neonatal sepsis. 
Firstly, it is important to establish that there is no significant statistic differences $(p=0,793)$ between the median from the ages in the cases $(23,5$ DS 4, 99) according to the median from the ages in the controls $(23,0$ DS 6,19$)$. Taking into consideration that $50 \%$ of the intermediate ages in the mother caused that part of the cases, were found between 20 and 26 years and for the mothers that formed a part of the controls $50 \%$ with intermediate ages that range from 19 and 28 years old. However, it's interesting to show how in the case of the adolescent moms, there was association in the significant statistic evidence $(\mathrm{p}=0,001)$ with the cases of early neonatal sepsis.

In relations to the age that they began their sexual or marital life; it was observed that inclusivley having the same medians for the cases $(16,0$ DS 0,945$)$ and for the controls $(16,0$ DS 0,971$)$ there exist significant differences in both groups ( $p=0,0001$ ), which was evident at the same time, the average ages in which sexual activity began in the cases 16,06 (IC 95\% 15,9-16,2) and the average in ages in the controls 15,6(IC 95\% 15,5-15,7). While considering how to establish significant statistic relations in the ages 18 and 16 years with the posibility to associate with the cases of early neonatal sepsis; Making evident that the inclusion when there is no association to 18 years $(\mathrm{p}=0,531)$, that clearly shows the relation of the cases of sepsis in women that are younger than 16 years old $(\mathrm{p}=0,001)$ to the women that are older than this age.

With relations to the other socio demographic variables, it was found that a significant statistic association from the mothers that are found affiliated to the subsedized regimen $(\mathrm{p}=0,041)$ and with level of education; for only having studies up to first grade $(\mathrm{p}=0,00001)$ and the possibility to develope early neonatal sepsis. In reference to the place of origin of the mother it is evident that having a rural origin $(\mathrm{p}=0,00001)$ determines a sigificant statistic association with the cases of early neonatal sepsis.

Another of the sociodemographic variables in which an important relationship with early neonatal sepsis was observed is the marital status ( $\mathrm{p}=0,00001)$. Mothers who report living with a partner (married or in a free union) show a statistically significant association regarding those that manifested not having a partner or for being single, widows or divorced. (See Table 1)

Table 1. Comparison of socio demographic characteristics in cases and controls of the mothers with pacients with early neonatal sepsis from a private clinic in Cartagena 2016-2017

\begin{tabular}{|c|c|c|c|c|c|c|c|c|c|c|c|}
\hline \multirow{2}{*}{$\begin{array}{l}\text { QUANTITATIVE } \\
\text { SOCIO } \\
\text { DEMOGRAPHIC } \\
\text { VARIABLES }\end{array}$} & \multicolumn{5}{|c|}{ Cases (186) } & \multicolumn{5}{|c|}{ Controls (369) } & \multirow[b]{2}{*}{ P-Value } \\
\hline & Mean & $\begin{array}{l}\text { IC } 95 \% \\
\text { for the } \\
\text { mean }\end{array}$ & Median & DS & RIC & Mean & $\begin{array}{l}\text { IC } 95 \% \\
\text { for the } \\
\text { mean }\end{array}$ & Median & DS & RIC & \\
\hline Age & 23,93 & $23,2-24,6$ & 23,5 & 4,99 & $20-26$ & 24,22 & $23,5-24,8$ & 23 & 6,19 & $19-28$ & $0,793 * * *$ \\
\hline $\begin{array}{l}\text { Age in that sexualy } \\
\text { active life began }\end{array}$ & 16,06 & $15,9-16,2$ & 16 & 0,945 & $15-17$ & 15,6 & $15,5-15,7$ & 16 & 0,971 & $15-16$ & $0,0001 * * *$ \\
\hline \multirow{2}{*}{$\begin{array}{c}\text { QUALITATIVE } \\
\text { SOCIO } \\
\text { DEMOGRAPHIC } \\
\text { VARIABLES } \\
\end{array}$} & \multirow{2}{*}{\multicolumn{2}{|c|}{ Categories }} & \multicolumn{2}{|c|}{ Cases (186) } & \multicolumn{2}{|c|}{ Controls (369) } & \multirow[b]{2}{*}{$X^{2}$} & & \multirow{2}{*}{\multicolumn{2}{|c|}{ P-Value }} & \\
\hline & & & $\mathbf{N}$ & $\%$ & $\mathbf{N}$ & $\%$ & & & & & \\
\hline \multirow{2}{*}{ Teen Mothers } & \multicolumn{2}{|r|}{ Yes } & 15 & $8,1 \%$ & 69 & $18,7 \%$ & \multirow{2}{*}{10,88} & & \multirow{2}{*}{\multicolumn{2}{|c|}{$0,001^{*}$}} & \\
\hline & & No & 171 & $91,9 \%$ & 300 & $81,3 \%$ & & & & & \\
\hline \multirow{2}{*}{ Health regimen } & \multicolumn{2}{|c|}{ Subsidaded } & 183 & $98,4 \%$ & 349 & $94,6 \%$ & \multirow{2}{*}{4,51} & & \multirow{2}{*}{\multicolumn{2}{|c|}{$0,041^{* *}$}} & \\
\hline & Cor & ributory & 3 & $1,6 \%$ & 20 & $5,4 \%$ & & & & & \\
\hline \multirow{2}{*}{ Origin } & \multicolumn{2}{|c|}{ Rural } & 42 & $22,6 \%$ & 5 & $1,4 \%$ & \multirow{2}{*}{71,87} & & \multirow{2}{*}{\multicolumn{2}{|c|}{$0,00001^{*}$}} & \\
\hline & & Irban & 144 & $77,4 \%$ & 364 & $98,6 \%$ & & & & & \\
\hline \multirow[t]{2}{*}{ Marital Status } & \multicolumn{2}{|c|}{$\begin{array}{l}\text { Married or in } \\
\text { common law } \\
\text { marriage }\end{array}$} & 128 & $68,8 \%$ & 101 & $27,4 \%$ & \multirow[t]{2}{*}{87,64} & & \multirow{2}{*}{\multicolumn{2}{|c|}{$0,00001 *$}} & \\
\hline & Single, & $\begin{array}{l}\text { Divorced or } \\
\text { idows }\end{array}$ & 58 & $31,2 \%$ & 268 & $72,6 \%$ & & & & & \\
\hline
\end{tabular}




\begin{tabular}{|c|c|c|c|c|c|c|c|}
\hline \multirow[t]{2}{*}{ Level of education } & $\begin{array}{c}\text { Elementary School } \\
\text { level }\end{array}$ & 86 & $46,2 \%$ & 80 & $21,7 \%$ & \multirow[t]{2}{*}{35,57} & \multirow[t]{2}{*}{$0,00001 *$} \\
\hline & High school & 100 & $53,8 \%$ & 289 & $78,3 \%$ & & \\
\hline \multirow{2}{*}{ Start of maritual life younger than 18 years old } & Yes & 178 & $95,7 \%$ & 357 & $96,7 \%$ & \multirow{2}{*}{0,39} & \multirow{2}{*}{$0,531 *$} \\
\hline & No & 8 & $4,3 \%$ & 12 & $3,3 \%$ & & \\
\hline \multirow{2}{*}{ Start of maritual life younger than 16 years old } & Yes & 47 & $25,3 \%$ & 147 & $39,8 \%$ & \multirow{2}{*}{11,54} & \multirow{2}{*}{$0,001^{*}$} \\
\hline & No & 139 & $74,7 \%$ & 222 & $60,2 \%$ & & \\
\hline
\end{tabular}

Source: Data obtained by project; Associated with the obstetric and neonatal factors with the cases of early neonatal sepsis in a private clinic in the city of Cartagena 2016-2017.

*Chi square and correction by Pearson; ** Chi square and correction by Fisher; *** U Mann-Whitney; ICR: Interquartile range; SD: Estándar Deviation.

In the case of neonatal variables, an important association was observed in the same way as the cases of early neonatal sepsis. When the weight was analyzed in grams from the newborns; evidence showed significant statistic differences $(p=0,0001)$ between the medians of the weights from the cases $(2768 \mathrm{~g})$ and the median of the weights in the controls ( $3224 \mathrm{~g}$ ). Taking all of this into consideration $50 \%$ of the intermediate weights from the newborns that formed part of the cases are found between 2500 and 3020 grams and for the controls $50 \%$ of the intermediate weights of the newborns range between 2959 and 3500 grams.

Also it is interesting to evidence, the significant statistic differences observed $(p=0,0001)$ in the values from the APGAR a minute after birth with an average of 7,73 points in the cases and an average of 8,09 points in the controls. No significant statistic association exist in the cases with early neonatal sepsis; in pacients that had values less than 7 after a minute of birth $(p=0,999)$ and those that had an APGAR point value of less than 7 after 5 minutes $(\mathrm{p}=0,999)$. Nevertheles, while analyzing the subject of respiratory difficulty evidence showed a significant statistic association $(\mathrm{p}=0,0001)$ between the newborns that have this to those that do not show any evidence of this at birth, with the possibility of developing cases of early neonatal sepsis.

Another variable associated to the cases of early neonatal sepsis is being premature $(p=0,0001)$, perhaps the most important from all of the neonatal variables, which is related to time, with the weight of the newborns and favors an association between the newborns weighing less than 1500 grams $(p=0,00001)$ and the ones weighing less than 2500 grams $(\mathrm{p}=0,00001)$ with the cases of early neonatal sepsis. Finally, for the case of sex of the newborn there was no significant statistic evidence associated $(\mathrm{p}=1,672)$ with the cases of early neonatal sepsis. (See Table 2$)$.

Table 2. Comparison of the Neonatal Characteristics of Cases and Controls in pacients with early neonatal sepsis from a private clinic in Cartagena 2016-2017

\begin{tabular}{|c|c|c|c|c|c|c|c|c|c|c|c|c|}
\hline \multirow{3}{*}{$\begin{array}{l}\text { QUANTITATIVE } \\
\text { NEONATAL } \\
\text { VARIABLES }\end{array}$} & \multicolumn{5}{|c|}{ Casos (186) } & \multicolumn{6}{|c|}{ Controles (369) } & \multirow{3}{*}{ P- Value } \\
\hline & \multirow[b]{2}{*}{ Mean } & \multirow{2}{*}{$\begin{array}{l}\text { IC } 95 \% \\
\text { forthe } \\
\text { mean }\end{array}$} & \multirow[b]{2}{*}{ Median } & \multirow[b]{2}{*}{ DS } & \multirow[b]{2}{*}{ RIC } & \multirow[b]{2}{*}{ Mean } & \multirow{2}{*}{\multicolumn{2}{|c|}{$\begin{array}{l}\text { IC } 95 \% \text { for the } \\
\text { mean }\end{array}$}} & \multirow[b]{2}{*}{ Median } & \multirow[b]{2}{*}{ In DS } & \multirow[b]{2}{*}{ RIC } & \\
\hline & & & & & & & & & & & & \\
\hline $\begin{array}{l}\text { Weight in grams of } \\
\text { the newborns }\end{array}$ & 2639,9 & $2560-2718$ & 2768,5 & 546,5 & $2500-3020$ & 3202,4 & 3160 & 3244 & 3224,00 & 0412,1 & $2950-3500$ & $0,0001 * * *$ \\
\hline $\begin{array}{l}\text { APGAR after a } \\
\text { minute of birth }\end{array}$ & 7,73 & $7,64-7,81$ & 8,00 & 0,611 & $7-8$ & 8,09 & 8,03 & 3,15 & 8,00 & 0,598 & $8-8$ & $0,0001 * * *$ \\
\hline \multirow{2}{*}{\multicolumn{4}{|c|}{ QUALITATIVE NEONATAL VARIABLES }} & & \multirow{2}{*}{\multicolumn{2}{|c|}{ Categories }} & Cases & (186) & \multicolumn{2}{|c|}{ Controls (369) } & \multirow{2}{*}{$X^{2}$} & \multirow{2}{*}{ P- Value } \\
\hline & & & & & & & $\mathbf{N}$ & $\%$ & $\mathbf{N}$ & $\%$ & & \\
\hline \multirow{2}{*}{ Premature } & & & & & Yes & & 100 & $53,8 \%$ & 25 & $6,8 \%$ & \multirow{2}{*}{156,4} & \multirow{2}{*}{$0,0001 *$} \\
\hline & & & & & No & & 86 & $46,2 \%$ & 344 & $93,2 \%$ & & \\
\hline \multirow{2}{*}{ Sex of the newborn } & & & & & Masculin & & 109 & $58,6 \%$ & 202 & $54,7 \%$ & \multirow{2}{*}{0,748} & \multirow{2}{*}{$1,672^{*}$} \\
\hline & & & & & Femenin & & 77 & $41,4 \%$ & 167 & $45,3 \%$ & & \\
\hline
\end{tabular}




\begin{tabular}{|c|c|c|c|c|c|c|c|}
\hline \multirow{2}{*}{ Less than 1500 grams } & Yes & 11 & $5,9 \%$ & 2 & $0,5 \%$ & \multirow{2}{*}{15,60} & \multirow{2}{*}{$0,00001 * *$} \\
\hline & No & 175 & $94,1 \%$ & 367 & $99,5 \%$ & & \\
\hline \multirow{2}{*}{ Less than 2500 grams } & Yes & 44 & $23,7 \%$ & 9 & $2,4 \%$ & \multirow{2}{*}{64,44} & \multirow{2}{*}{$0,00001 *$} \\
\hline & No & 142 & $76,3 \%$ & 360 & $97,6 \%$ & & \\
\hline \multirow{2}{*}{ APGAR less than 7 after a minute of birth } & Yes & 2 & $1,1 \%$ & 3 & $0,8 \%$ & \multirow{2}{*}{0,095} & \multirow{2}{*}{$0,999 * *$} \\
\hline & No & 184 & $98,9 \%$ & 366 & $99,2 \%$ & & \\
\hline \multirow{2}{*}{ APGAR less than 7 after 5 minutes } & Yes & 4 & $2,2 \%$ & 9 & $2,4 \%$ & \multirow{2}{*}{0,045} & \multirow{2}{*}{$0,999 * *$} \\
\hline & No & 182 & $97,8 \%$ & 360 & $97,6 \%$ & & \\
\hline \multirow{2}{*}{ Respiratory Difficulty } & Yes & 89 & $47,8 \%$ & 27 & $7,3 \%$ & \multirow{2}{*}{122,8} & \multirow{2}{*}{$0,0001 *$} \\
\hline & No & 97 & $52,2 \%$ & 342 & $92,7 \%$ & & \\
\hline
\end{tabular}

Source: Data obtained by project; Associated with the obstetric and neonatal factors with the cases of early neonatal sepsis in a private clinic in the city of Cartagena 2016-2017

*Chi square and correction by Pearson; ** Chi square and correction by Fisher; *** U Mann-Whitney; ICR: Interquartile range; SD: Estándar Deviation.

There is important evidence that relates from the analysis of the obstetric variables with the cases of early neonatal sepsis. Firstly, it is important to establish that there is no evidence of significant statistic differences $(p=0,076)$ between the medians of the number of pregnancies from the mothers that formed part of the control cases regarding those in the controls. However, it is interesting to evidence that respecting the gestational age at the moment of birth there where significant statistic differences $(p=0,0001)$ between the median at the time of the gestation in the cases (36 semanas DS 3,47) regarding the median at the time of gestation in the controls (39 semanas DS 1, 62). Considering that $50 \%$ of gestational ages at the moment of birth in the cases ranges from 34 and 39 weeks and in the controls averaging between 38 and 39 weeks.

In relation to the number of births there is a significant statistic evidence difference $(p=0,0001)$ between the observed averages in the cases $(1,04 \mathrm{DS} 1,03)$ regarding the average in the controls $(0,70 \mathrm{DS} 1,03)$. The same occurs with the number of cesarean section; showing significant statistic evidence difference $(p=0,029)$ between the number of cesarean sections conducted in the controls (0, 76 IC 95\% 0, $69-0,82)$. More than the differences found in the groups; no important evidence was associated between the type of birth and the possibility to develope early neonatal sepsis $(\mathrm{p}=0,050)$.

Considering the number of prenatal controls conducted in both groups; it is important to define that there is a significant statistic evidence difference $(\mathrm{p}=0,002)$. In average the controls $(4,32$ IC $95 \% 4,12-4,51)$ conducted more prenatal controls in the group of the cases (4, 08 IC 95\% 3, 82 - 4, 34). Taking this into consideration and evaluating the possible associations in the assistance of prenatal control and the possible appearance of early prenatal sepsis, showed that, attending or not the prenatal controls does not associate with the cases of sepsis ( $p=$ 0,402); at the same time going to 4 prenatal controls does not have an important impact in the appearance of early sepsis $(p=0,083)$; however, going to 5 prenatal controls is associated $(p=0,004)$ with the protection to avoid the appearance of early neonatal sepsis.

Besides than the type of birth; there was no evidence in association with early neonatal sepsis in the variables with the antecedent of intrauterine growth restriction (IUGR) $(p=0,600)$ and multiple pregnancies $(p=0,353)$.

The most important associated variable, with early neonatal sepsis, between the obstetric variables is the premature membrane rupture (PMR). Even when there is relation to PMR $>6$ hours there is evidence of a significant statistic association $(p=0,0001)$ with the cases of early sepsis. Evidently while reviewing the cases of PMR for more time, that is to say more than 18 hours said association was also identified $(p=0,00001)$. Another important factor to explain the appearance of early neonatal sepsis is a condition from the mother known as chorioamnionitis which shows clear evidence of significant statistic association. $(\mathrm{p}=0,00001)$. (See Table 3 ) 
Table 3. Comparison of the Obstetric Characteristics of the Cases and Controls in pacients with early neonatal sepsis in a private clinic in Cartagen 2016-2017

\begin{tabular}{|c|c|c|c|c|c|c|c|c|c|c|}
\hline \multirow{2}{*}{$\begin{array}{l}\text { QUANTITATIVE OBSTETRIC } \\
\text { VARIABLES }\end{array}$} & \multicolumn{5}{|c|}{ Cases (186) } & \multicolumn{4}{|c|}{ Controles (369) } & \multirow[b]{2}{*}{ P- Value } \\
\hline & Mean & $\begin{array}{l}\text { IC } 95 \% \text { for } \\
\text { the mean }\end{array}$ & Median & DS & RIC & Mean & $\begin{array}{l}\text { IC } 95 \% \text { fro } \\
\text { the mean }\end{array}$ & Median & DS RIC & \\
\hline $\begin{array}{l}\text { Gestational age at the time of } \\
\text { bith }\end{array}$ & 35,6 & $35,1-36,1$ & 36,0 & 3,47 & $34-39$ & 38,4 & $38,3-38,6$ & 39,0 & $1,62 \quad 38-39$ & $0,0001 * * *$ \\
\hline Number of prenatal controls & 4,08 & $3,82.4,34$ & 5,00 & 1,83 & $3,75-5,00$ & 4,32 & $4,12-4,51$ & 5,00 & $1,83 \quad 4-5$ & $0,002 * * *$ \\
\hline Number of pregnancies & 1,77 & $1,61-1,94$ & 1,00 & 1,15 & $1-2$ & 1,60 & $1,50-1,71$ & 1,00 & $1,15 \quad 1-2$ & $0,076^{* * *}$ \\
\hline Number of births & 1,04 & $0,89-1,19$ & 1,00 & 1,03 & $0-1$ & 0,70 & $0,63-0,78$ & 1,00 & $1,03 \quad 0-1$ & $0,0001 * * *$ \\
\hline Number of cesarean sections & 0,65 & $0,55-0,74$ & 1,00 & 0,68 & $0-1$ & 0,76 & $0,69-0,82$ & 1,00 & $0,68 \quad 0-1$ & $0,029 * * *$ \\
\hline \multirow{2}{*}{$\begin{array}{c}\text { QUANTITATIVE OBSTETRIC } \\
\text { VARIABLES }\end{array}$} & \multirow{2}{*}{\multicolumn{2}{|c|}{ Categories }} & \multicolumn{2}{|c|}{ Cases (186) } & \multicolumn{2}{|c|}{ Controls (369) } & \multirow{2}{*}{$X^{2}$} & \multirow{2}{*}{\multicolumn{2}{|c|}{ P-Value }} & \\
\hline & & & $\mathbf{N}$ & $\%$ & $\mathbf{N}$ & $\%$ & & & & \\
\hline \multirow{2}{*}{ Type of birth } & & Vaginal & 98 & $52,7 \%$ & 162 & $43,9 \%$ & \multirow{2}{*}{3,833} & \multirow{2}{*}{\multicolumn{2}{|c|}{$0,050^{*}$}} & \\
\hline & & Cesárea & 88 & $47,3 \%$ & 207 & $56,1 \%$ & & & & \\
\hline \multirow{2}{*}{ IUGR Background } & & Yes & 5 & $2,7 \%$ & 13 & $3,5 \%$ & \multirow{2}{*}{0,275} & \multirow{2}{*}{\multicolumn{2}{|c|}{$0,600^{*}$}} & \\
\hline & & No & 181 & $97,3 \%$ & 356 & $96,5 \%$ & & & & \\
\hline \multirow{2}{*}{ Assistance for prenatal control } & & Yes & 165 & $88,7 \%$ & 318 & $86,2 \%$ & \multirow{2}{*}{0,702} & \multirow{2}{*}{\multicolumn{2}{|c|}{$0,402 *$}} & \\
\hline & & No & 21 & $11,3 \%$ & 51 & $13,8 \%$ & & & & \\
\hline \multirow{2}{*}{$\begin{array}{c}\text { Assistance for at least } 4 \text { prenatal } \\
\text { conrols }\end{array}$} & & Yes & 140 & $75,3 \%$ & 301 & $81,6 \%$ & \multirow{2}{*}{3,010} & \multirow{2}{*}{\multicolumn{2}{|c|}{$0,083 *$}} & \\
\hline & & No & 46 & $24,7 \%$ & 68 & $18,4 \%$ & & & & \\
\hline \multirow{2}{*}{$\begin{array}{c}\text { Assistance for at least } 5 \\
\text { prenatal conrols }\end{array}$} & & Yes & 105 & $56,5 \%$ & 254 & $68,8 \%$ & \multirow{2}{*}{8,301} & \multirow{2}{*}{\multicolumn{2}{|c|}{$0,004 *$}} & \\
\hline & & No & 81 & $43,5 \%$ & 115 & $31,2 \%$ & & & & \\
\hline \multirow{2}{*}{$\begin{array}{l}\text { Premature membrane rupture } \\
\text { with more than } 18 \text { hours }\end{array}$} & & Yes & 95 & $51,1 \%$ & 17 & $4,6 \%$ & \multirow{2}{*}{165,7} & \multirow{2}{*}{\multicolumn{2}{|c|}{$0,00001^{*}$}} & \\
\hline & & No & 91 & $48,9 \%$ & 352 & $95,4 \%$ & & & & \\
\hline \multirow{2}{*}{ Chorioamnionitis } & & Yes & 23 & $12,4 \%$ & 3 & $0,8 \%$ & \multirow{2}{*}{36,96} & & $000001 * *$ & \\
\hline & & No & 163 & $87,6 \%$ & 366 & $99,2 \%$ & & & & \\
\hline Premature membrane ruture & & Yes & 161 & $86,6 \%$ & 194 & $52,6 \%$ & 11 & & $00001 *$ & \\
\hline with more than 6 hours & & No & 25 & $13,4 \%$ & 175 & $47,4 \%$ & 然 & & 0,0001 & \\
\hline Multinle nreonancies & & Yes & 2 & $1,1 \%$ & 10 & $2,7 \%$ & 039 & & $0353 * *$ & \\
\hline & & No & 184 & $98,9 \%$ & 359 & $97,3 \%$ & & & & \\
\hline
\end{tabular}

Source: Data obtained by project; Associated with the obstetric and neonatal factors with the cases of early neonatal sepsis in a private clinic in the city of Cartagena 2016-2017.

*Chi square and correction by Pearson ** Chi square and correction by Fisher *** U Mann-Whitney ICR: Interquartile range; SD: Estándar Deviation.

In relation to the variables of a maternal infectious pathology and its association with the cases of early neonatal sepsis, there is important evidence that determines that in all of the cases the variables showed significant statistic association. In the cases that were studied of the mothers that presented a background of sexualy transmitted infection, which does not implicate that they had such infecction at the time of birth, there was a significant statistic association identifed $(\mathrm{p}=0,0001)$ with the cases of early neonatal sepsis. There was also an investigation regarding the pressence of a background with yeast infections $(p=0,0001)$ and urinary tract infections $(U T I)(p=0,038)$ it was proven that the statistic characteristics associated to the cases of early neonatal sepsis. For the case of the mother with the pathologies such as maternal fever, which in the majority of the cases is presented at birth, also shows significant statistic evidence associated $(p=0,0001)$ to the cases of early neonatal sepsis. (See Table 4) 
Table 4. Comparison of the Characteristics related to the pathology of maternal infections of the Cases and Controls in pacients with early neonatal sepsis in a private clinic in Cartagen 2016-2017

\begin{tabular}{|c|c|c|c|c|c|c|c|}
\hline \multirow{2}{*}{ QUALITATIVE VARIABLES } & \multirow{2}{*}{ Categories } & \multicolumn{2}{|c|}{ Cases (186) } & \multicolumn{2}{|c|}{ Controls (369) } & \multirow{2}{*}{$X^{2}$} & \multirow{2}{*}{ P-Value } \\
\hline & & $\mathbf{N}$ & $\%$ & $\mathbf{N}$ & $\%$ & & \\
\hline \multirow{2}{*}{ Maternal Fever } & Yes & 67 & $36 \%$ & 40 & $10,8 \%$ & \multirow{2}{*}{50,38} & \multirow{2}{*}{$0,0001 *$} \\
\hline & No & 119 & $64 \%$ & 329 & $89,2 \%$ & & \\
\hline \multirow{2}{*}{ Yeast Infections } & Yes & 31 & $16,7 \%$ & 15 & $4,1 \%$ & \multirow{2}{*}{25,83} & \multirow{2}{*}{$0,0001^{*}$} \\
\hline & No & 155 & $83,3 \%$ & 354 & $95,9 \%$ & & \\
\hline \multirow{2}{*}{ Backgroud to sexualy transmitted diseases } & Yes & 27 & $14,5 \%$ & 7 & $1,9 \%$ & \multirow{2}{*}{34,24} & \multirow{2}{*}{$0,0001 *$} \\
\hline & No & 159 & $85,5 \%$ & 362 & $98,1 \%$ & & \\
\hline \multirow{2}{*}{ Urinary Tract Infections } & Yes & 11 & $5,9 \%$ & 9 & $2,4 \%$ & \multirow{2}{*}{4,29} & \multirow{2}{*}{$0,0381^{*}$} \\
\hline & No & 175 & $94,1 \%$ & 360 & $97,6 \%$ & & \\
\hline
\end{tabular}

Source: Data obtained by project; Associated with the obstetric and neonatal factors with the cases of early neonatal sepsis in a private clinic in the city of Cartagena 2016-2017.

*Chi square and correction by Pearson ** Chi square and correction by Fisher.

\section{Multivariated analysis on the association between obstetric, neonatal and maternal infectious related pathology variables, with the pressence of early neonatal sepsis}

During the second fase the multivariated analysis continued, using the logistic binary regression, where it was being considered the variables in which the bivariated analysis presented a significant statistic association with those who, although they were not associated to have clinical importance and relevance with the pressence of early neonatal sepsis and considering the multicolinearity analysis to help include the variables that do not apport to the model. For this reason the age of the mother was ajusted, the sex of the neontal, the type of birth, the number of prenatal controls and the age in which they began to have sexual activity; showing the risk to develope early neonatal sepsis in the case of the mothers that have a premature membrane rupture $>18$ horas (OR 9,57 IC 95\% 4,12-22,26), the risk of sepsis for being a premature newborn (OR 8,19 IC 95\% 3,66-18,3), the pressence of maternal fever (OR 6,49 IC 95\% 3,43-12,3), and the case of the marital status considering the risk of the mothers that live with a significant other to those who do not (OR 5,89 IC 95\% 3,42-10,15) and the level of education considering the risk for those who only completed elementary school (OR 4,80 IC 95\% 2,63-8,77). (See Table 5).

Table 5. Analysis of the logistic regression from the effect of the indipendent variables over the developement of early neonatal sepsis ajusted by the age of the mother, sex of the neonatal, type of birth and the age in which they began to have sexual activity

\begin{tabular}{llllllll}
\hline \multirow{2}{*}{ Variables } & \multirow{2}{*}{ OR Raw } & \multicolumn{2}{l}{ IC 95\% } & \multirow{2}{*}{ OR Ajusted (Exp B) } & & \multicolumn{2}{c}{ IC 95\% for (EXP $\beta)$} \\
\cline { 3 - 5 } & & LI & LS & & LI & LS \\
\hline PRM with more than 18 hours & 21,61 & 12,2 & 38,04 & 9,578 & 4,12 & 22,26 \\
\hline Marital status & 5,856 & 3,98 & 8,61 & 5,897 & 3,42 & 10,15 \\
\hline Prematurity & 16,0 & 9,725 & 26,32 & 8,195 & 3,66 & 18,33 \\
\hline Maternal Fver & 4,63 & 2,97 & 7,221 & 6,495 & 3,43 & 12,30 \\
\hline Level of educaton & 3,106 & 2,125 & 4,543 & 4,805 & 2,63 & 8,77 \\
\hline
\end{tabular}

Ajust for the age of the mother, sex of the neonatal, type of birth, number of prenatal controls and the age in which they began to have sexual activity.

Source: Data obtained by project; Associated with the obstetric and neonatal factors with the cases of early neonatal sepsis in a private clinic in the city of Cartagena 2016-2017.

\section{Discussion}

The results of this investigation are comparable to those reported in the literature. 
With the relation to the premature rupture of membranes $>18$ hours the results of this investigation where similar to the ones obtained internationally by Fareedul et al. (Fareedul, Shamshad, \& Prakash, 2014) that observed statistic significances $(\mathrm{p}=0,009)$, the same as Goulart et al. (Goulart, Fraga Valle, Dal Pizzol, \& Labor Cancelier, 2013) and Pérez et al., (Pérez, Lona, \& Quile, 2015) with PRM > 18 hours; for the case of Leal et al. (Leal, y otros, 2012), where a significant statistic difference was observed after 12, 24 and 48 hours of PMR. Gyamfi y Son (Gyamfi Bannerman \& Son, 2014), having analyzed the time in hours of the PMR between the two groups that developed neonatal sepsis and those in which there was not found an existing significant statistic difference $(\mathrm{p}=0,020)$ between both groups.In one of the studies where they measured the risk of sepsis in mothers with chorioamnionitis Romero et al. (Romero Maldonado, Ortega Cruz, \& Galvan Contreras, 2013), where it was determined that PMR $>18$ is an important background associated to the appearance of early neonatal sepsis.

At the level of Barrios et al. (Barrios, Rodríguez, \& Sánchez), a study was conducted in the city of Barranquilla, in the INCU, where they discovered similar results to the ones obtained in this investigation. However, in an investigation taken place by Genes et al. (Genes, Lacarrubba, Mir, Céspedes, \& Mendieta, 2013), in a population of newborns born with low weight; after conducting the regression logistic analysis as a depenent variable or constant early sepsis there was no significant influence observed from, PMR $>18 \mathrm{~h}(\mathrm{p}=0,572)$. Recent studies by Gebremedhin et al. (Gebremedhin, Berhe, \& Gebrekirstos, 2016), the same as (Alam, Saleem, Shaikh, Munir, \& Qadir, 2014), and Drassinower et al. (Drassinower, Friedman, Običan, Levin, \& Gyamfi-Bannerman, 2016), showed that there is still an important obstetric risk factor considering an early neonatal sepsis. In the patients with premature rupture of membranes, the fisiopathological event that originated an intra amniotic infecction, especially if the rupture happens at an early gestatinal age, even though there is still a discussion regarding if the infecction is the cause or consequence of the complication.

With the relation of the prematurity the results of this investigation were similar to those obtained by Pérez et al., (Pérez, Lona, \& Quile, 2015) born with the gestational age $<37$ weeks (OR 3,14 IC 95\% 1,58 -6,22), the same as Leal et al. (Leal, y otros, 2012), prematurity (OR 1,08 IC 95\% 1,03-1,14), and Goulart et al. (Goulart, Fraga Valle, Dal Pizzol, \& Labor Cancelier, 2013), post term (OR 9,33 IC 95\% 4,06-21,94). There are very few studies in which there was no association between prematurity and early neonatal sepsis, in the case of Fareedul et al. (Fareedul, Shamshad, \& Prakash, 2014), where there is no determined statistic risk. According to the WHO (World Health Organization) it is believed worldwide, that prematurity is the frst cause of mortality in kids younger than 5 years old. In almost all of the countries that dispose of this reliable data according to the growing number of premature births. The spontaneuos premature birth, before the 37 weeks of gestation, may cause this with no apparent reason. In other cases, the cause of this is associated to different factors like is the yeast infection and by the cases of teen mothers in which the first of these is associated with early sepsis in this present study. The principal reasons associated to the presence of early neonatal sepsis in preterm newborns is the immaturity of their natural barriers (poorly developed epidermis); a decreased number and function of neutrphils, monocytes and macrophages (chemotaxis, phagocytosis and microbicide); decreased number and function in NK cells, low cytokines production, defenses and compliment levels.

With relations to the pregnant women with maternal fever while giving birth, similar results were obtained by Pérez et al. (Pérez, Lona, \& Quile, 2015), where there is a higher risk of SNT (OR 6, 04 IC 95\% 1, 54- 23, 6) with more frecuency in premature newborns with low weight, where they developed a protocal for the microbiological studies for the newborns and mothers that show clinical manifestations for maternal fever.

Taking into account the socio-demographic variables such as the level of education; similar results to those obtained in a cohort study by Díaz and Chávez (Diaz \& Chavez, 2015), in where they found statistical differences in the level of education according to age groups and the presence of maternal complications in adolescents and adults. However, in the study by Anaya et al. (AnayaPrado, y otros, 2017), there was no evidence of association with maternal education with cases of early neonatal sepsis, or in the case of primary or secondary study and much less for those who had bachelor's degree program.

In recent years it has been found in some studies, that perinatal complications occur more in teenage mothers in which if family is dysfunctional, constitution and most are single mothers or divorced, in addition to having a low educational level, where the emphasis is on sex education (Velasteguí Eguez, 2018). However, these results differ from those obtained in the present study; considering that the majority of teenage mothers had more than 5 perinatal controls, so were treated as high-risk pregnancies, which in essence was a protective factor to avoid cases of early neonatal sepsis in their children, associating SMT much more those mother living with partners, and that they are adults. 


\section{Conclusions}

In relation to the cases from the mothers with PRM, maternal fever and premature newborn makes an evident causal association for early neonatal sepsis. In the case of the sociodemographic variables like level of education and marital status makes it important to continue the studies that show major evidence in the appearance of SNT.

The presence of maternal infectious pathology, such as vaginal infection present in the study population, was the determining factor to explain the cases of premature membrane rupture over the 18 hours, which requires that in the prenatal control to define actions for a better management to vaginal infections during the pregnancy. On the other hand, most of the mothers with maternal fever show infections that transcend to the newborn and not necessarily without maternal pathologies exclusively, so it must be set to these mothers better administration of prophylactic antibiotic therapy maternal mortality, which could reduce the infection, slow labor and reduce cases of prematurity. Finally, there is a clear need to perform cost-benefit studies in relation to the implementation and programs to detect and treatment of infections in pregnant women before 20 weeks of gestation, this has been shown to reduce low birth weight in preterm infants and premature birth.

\section{Competing Interests Statement}

The authors declare that there are no competing or potential conflicts of interest.

\section{References}

Alam, M. M., Saleem, A. F., Shaikh, A. S., Munir, O., \& Qadir, M. (2014). Neonatal sepsis following prolonged rupture of membranes in a tertiary care hospital in Karachi, Pakistan. Journal of infection in developing countries, 8(1), 67-73. https://doi.org/10.3855/jidc.3136

Anaya-Prado, R., Valero-Padilla, C., Sarralde-Delgado, A., Sánchez-González, J. M., Montes-Velázquez, L., \& Gil-Villarreal, F. (2017). Sepsis neonatal temprana y factores asociados. Revista Médica del Instituto Mexicano del Seguro Social, 55(3).

Barrios, V., Rodríguez, C., \& Sánchez, R. (s.f.). Factores de Riesgo asociados a mortalidad neonatal en Unidades de Cuidado Intensivos Neonatales. Estudio Multicentrico, Barranquilla Enero 2012-Mayo 2013. Biociencias, $8(1), 45-51$.

Cabanillas Castillo, G. R. (2014). Caracteristicas de la sepsis neonatal en el Hospital Almanzor Aguinaga Asenjo durante los a-os 2011-2017. Rev. cuerpo méd, 6-10.

Coronel, W. (2009). Sepsis neonatal. Revista de Enfermedades Infecciosas en Pediatría, 58-68.

Drassinower, D., Friedman, A., Običan, S., Levin, H., \& Gyamfi-Bannerman, C. (June de 2016). Prolonged latency of preterm premature rupture of membranes and risk of neonatal sepsis. Obstet Gynecol, 214(6), 743.e1-6.

Fareedul, H., Shamshad, K., \& Prakash, S. (2014). Clinical Profile and Risk factors in Neonatal Sepsis. IOSR

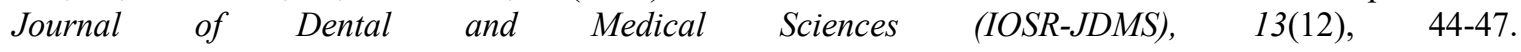
https://doi.org/10.9790/0853-131264447

Gebremedhin, D., Berhe, H., \& Gebrekirstos, K. (Mayo de 2016). Risk Factors for Neonatal Sepsis in Public Hospitals of Mekelle City, North Ethiopia, 2015: Unmatched Case Control Study . Plos one journals, 11(5).

Genes, L., Lacarrubba, J., Mir, R., Céspedes, E., \& Mendieta, E. (Agosto de 2013). Sepsis neonatal. Caracterización en Recién Nacidos de muy bajo peso. Experiencia de once a-os. Pediatr. (Asunción), 40(2), 145-154.

Goulart, A. P., Fraga Valle, C., Dal Pizzol, F., \& Labor Cancelier, A. C. (Junho de 2013). Fatores de Risco para o Desenvolvimento de Sepse Neonatal Precoce em Hospital da Rede Pública do Brasil. Revista Brasileira de Terapia Intensiva, 18(2).

Gyamfi Bannerman, C., \& Son, M. (Noviembre de 2014). Preterm Premature Rupture of Membranes and the Rate of Neonatal Sepsis After Two Courses of Antenatal Corticosteroids. Obstet Gynecol, 125(5), 999-1003.

Leal, Y. A., Álvarez Nemegyei, J., Velázquez, J. R., Rosado Quiab, U., Diego Rodríguez, N., Paz Baeza, E., \& Dávila Velázquez, J. (2012). Risk factors and prognosis for neonatal sepsis in southeastern Mexico: analysis of a four-year historic cohort follow-up. Biomed Central Pregnancy Childbirth, 12(48). https://doi.org/10.1186/1471-2393-12-48

Ministerio de salud y protección social. (2016). Analisis de Situación de salud (ASIS). Colombia.

Ortiz Maldonado, F. (2014). Complicaciones neonatales asociadas a la ruptura de membranas amnioticas en recien 
nacidos de pretermino. Rev Mex Pediatr, 169-173.

Pe-a, C., Pinzón, Y., Forero, Y., Pantoja, J., Giraldo, L., Bastidas, A., \& Agudelo, S. (Octubre-Diciembre de 2016). Características de pacientes ingresados a la unidad de cuidado intensivo neonatal en la Clínica Universidad de La Sabana. Salud UIS, 48(4).

Pérez, R. O., Lona, J. C., \& Quile, M. (2015). Sepsis neonatal temprana, incidencia y factores de riesgo asociados en un hospital público del occidente de México. Rev Chilena Infectol, 32(4), 387-392.

Romero Maldonado, S., Ortega Cruz, M., \& Galvan Contreras, R. (2013). Riesgo de sepsis neonatal temprana en recién nacidos de madre con corioamnionitis. Estudio de casos y controles. Perinatol Reprod Hum, 27(4), 217-220.

\section{Copyrights}

Copyright for this article is retained by the author(s), with first publication rights granted to the journal.

This is an open-access article distributed under the terms and conditions of the Creative Commons Attribution license (http://creativecommons.org/licenses/by/4.0/). 